\title{
Chair-Sitting Exercise Intervention Does Not Improve Respiratory Muscle Function in Mechanically Ventilated Intensive Care Unit Patients
}

\author{
Mei-Yu Chang RN MSc, Li-Yin Chang RN MSc, Yi-Chia Huang PhD RD, and \\ Kuei-Man Lin RN MSc, and Chien-Hsiang Cheng MD PhD
}

\begin{abstract}
BACKGROUND: Chair-sitting may allow for more readily activated scalene, sternocleidomastoid, and parasternal intercostal muscles, and may raise and enlarge the upper thoracic cage, thereby allowing the thoracic cage to be more easily compressed. OBJECTIVE: To evaluate the effect of chair-sitting during exercise training on respiratory muscle function in mechanically ventilated patients. METHODS: We randomized 16 patients to a control group and 18 patients to a chairsitting group. The patients in the chair-sitting group were transferred by 2 intensive care unit nurses from bed to armchair and rested for at least $30 \mathrm{~min}$, based on the individual patient's tolerance. We measured heart rate, blood pressure, $S_{p o}$, and respiratory rate. In the treatment group, before transferring the patient from bed to armchair, and $30 \mathrm{~min}$ after the completion of chair-sitting we measured respiratory muscle function variables, including the ratio of respiratory rate (f) to tidal volume $\left(\mathrm{V}_{\mathrm{T}}\right), \mathrm{S}_{\mathrm{pO}_{2}}$, maximum inspiratory pressure $\left(\mathrm{P}_{\mathrm{Imax}}\right)$ and maximum expiratory pressure $\left(\mathbf{P}_{\text {Emax }}\right)$. In the control patients we took those same measurements while the patient was in semirecumbent position, before and after treatments, for at least 6 days or until the patient was discharged from the intensive care unit or died. RESULTS: The 2 groups did not significantly differ in age, sex, or clinical outcomes. Respiratory rate, $\mathrm{V}_{\mathrm{T}}, \mathbf{f} / \mathrm{V}_{\mathrm{T}}, \mathrm{S}_{\mathrm{pO}_{2}}, \mathbf{P}_{\mathrm{Imax}}$, and $\mathbf{P}_{\mathrm{Emax}}$ were not significantly better in the chair-sitting group. The study period significantly improved respiratory rate, $V_{T}, P_{\text {Imax }}$, and $P_{\text {Emax }}$ (all $P<.001$ ), but not $\mathbf{f} / V_{T}$. CONCLUSIONS: Six days of chair-sitting exercise training did not significantly improve respiratory muscle function in mechanically ventilated patients. Key words: exercise training; chair-sitting; respiratory muscle function; mechanical ventilation. [Respir Care 2011;56(10):1533-1538. (C) 2011 Daedalus Enterprises]
\end{abstract}

\section{Introduction}

The lack of physical activity in mechanically ventilated critically ill patients reduces respiratory muscle strength ${ }^{1}$ and may prolong ventilator dependence and intensive care unit (ICU) stay. Early physiotherapy, including positioning (eg, upright, prone, or side lying position) and mobi-

\footnotetext{
Ms Mei-Yu Chang is affiliated with the Surgical Intensive Care Unit, and Ms Li-Yin Chang is affiliated with the Department of Nursing, Taichung Veterans General Hospital, Taichung, Taiwan. Dr Huang is affiliated with School of Nutrition, Chung Shan Medical University, Taichung, Taiwan. Ms Lin is affiliated with Department of Nursing, HungKuang University and Institute of Medicine, Chung Shan Medical University, Taichung, Taiwan. Dr Cheng is affiliated with the Department of Critical Care and Respiratory Therapy, and the Intensive Care Unit, Taichung Veterans General Hospital, and with the Department of Nursing, HungKuang University, Taichung, Taiwan.
}

lization (eg, getting out of bed via mechanical lifting machine, sitting on the edge of the bed, standing, transferring from bed to chair, and walking), have been advocated to prevent skeletal muscle weakness, reduce the work of breathing, and shorten mechanical ventilation in the ICU. ${ }^{2-5}$ An early study indicated that vital capacity decreased follow-

\footnotetext{
This study was partly supported by grant TCVGH-967420A from the Taichung Veterans General Hospital, Taichung, Taiwan.

The authors have disclosed no conflicts of interest.

Correspondence: Chien-Hsiang Cheng MD PhD, Department of Critical Care, Taichung Veterans General Hospital, Taichung, Taiwan, Republic of China. E-mail: ych@csmu.edu.tw.
}

DOI: $10.4187 /$ respcare.00938 


\section{ChaIR-SitTing EXercise INTERVENTION}

ing a change of position from sitting to supine position. ${ }^{6}$ Patients with chronic asthma had significantly higher maximum expiratory pressure $\left(\mathrm{P}_{\text {Emax }}\right)$ in a sitting leaning-forward position than in the supine position $(P<.001){ }^{7}$ Jenkins et $\mathrm{al}^{8}$ studied the effects of positioning on functional residual capacity in normal subjects and in male patients before and after coronary artery surgery. In the normal subjects and patients, functional residual capacity was higher in the chairsitting position than the lying position. ${ }^{8}$ However, other studies found that the upright sitting position did not improve tidal volume $\left(\mathrm{V}_{\mathrm{T}}\right)$, total lung capacity, or functional residual capacity in intubated subjects with abdominal distention, ascites, or obesity, ${ }^{9}$ and healthy individuals. ${ }^{10}$

Chair-sitting (ie, transferring from bed to chair and sitting) combines both positioning and mobilization techniques, and we have applied this technique in our surgical ICU to improve mechanically ventilated patients' respiratory muscle strength. Theoretically, chair-sitting could help the scalene, sternocleidomastoid, and parasternal intercostal muscles be more readily activated, and could raise and enlarge the upper thoracic cage, thereby allowing the thoracic cage to be more easily compressed and increasing $\mathrm{P}_{\text {Emax }}{ }^{10}$ However, there have been few studies on the efficacy of this physiotherapy on respiratory muscle and weaning outcomes in the ICU. We conducted a randomized controlled trial to evaluate the effect of chair-sitting on the respiratory muscles of mechanically ventilated patients in a surgical ICU, and hypothesized that the chair-sitting technique would benefit their respiratory muscle function.

\section{Methods}

This study was approved by the institutional review board of Taichung Veterans General Hospital. Informed consent was obtained from all patients and/or their legal representatives.

\section{Study Design}

This was a prospective randomized controlled study, conducted in a 24-bed surgical ICU at Taichung Veterans General Hospital, which is a 1,359-bed medical center in central Taiwan.

\section{Patients}

All patients admitted or transferred to the surgical ICU were screened for potential study participation. Patients who required mechanical ventilation for at least 72 hours and who could be transferred by 2 surgical ICU nurses from bed to armchair without a mechanical lifting machine were considered for enrollment. The patients were orally intubated with a cuffed endotracheal tube (inner-diameter range $7-8 \mathrm{~mm}$ ) and mechanically ventilated (840, Puritan
Bennett, Carlsbad, California) in a volume or pressure ventilation mode, with a decremental inspiratory flow. Applied PEEP was titrated to $3-5 \mathrm{~cm} \mathrm{H}_{2} \mathrm{O}$ to maintain the elastic recoil pressure of the respiratory system, so the physiologic PEEP was kept constant throughout the study. The peak airway pressure was kept between 30 and $40 \mathrm{~cm}$ $\mathrm{H}_{2} \mathrm{O}$, to prevent ventilator-induced lung injury.

We excluded patients who were under 18 years old, clinically unstable, unconscious, had received neurosurgery or cardiovascular surgery, had self-extubated, had postoperative abdominal wound dehiscence, or had received a tracheostomy. At enrollment we recorded age, sex, height, diagnosis, and Acute Physiology and Chronic Health Evaluation II (APACHE II) score. During the study we daily measured patient weight and calculated body mass index. From the medical records we obtained ICU and hospital stay and ventilator days.

\section{Intervention}

Thirty-four patients were randomly assigned to either the control group $(n=16)$ or the treatment (chair-sitting) group $(n=18)$. The random assignment was based on a computerized randomization scheme with sealed opaque envelopes. All interventions were performed for at least 6 days, or until the patient was discharged from the ICU or died. If a patient was weaned or discharged from the ICU earlier than 6 days, each measurement would be treated as a missing value. Patients in the control group were requested to lie in a comfortable position in between the supine and the semirecumbent position, and none of the control patients received any type of physical therapy during the study. Patients in the chair-sitting group were transferred by 2 ICU nurses from bed to armchair and rested for at least $30 \mathrm{~min}$ to a maximum of $120 \mathrm{~min}$, based on each patient's tolerance. We did not use a mechanical lifting machine. In the 18 patients randomized to the intervention group, the chair-sitting technique was performed at least once a day in 15 patients, and a minimum of 3 times a week in 3 patients. Before each mobilization, analgesia was given if needed.

\section{Measurements}

In the treatment group, outcome measurements were taken before transferring the patient from bed to armchair, and $30 \mathrm{~min}$ after the completion of chair-sitting. In the control group, measurements were taken with the patient in the semirecumbent position, before and after treatment times, similar to those of the treatment group. The primary outcome of respiratory muscle endurance was measured with the rapid shallow breathing index, which is the ratio of spontaneous breathing frequency to $\mathrm{V}_{\mathrm{T}}\left(\mathrm{f} / \mathrm{V}_{\mathrm{T}}\right)$, a reliable predictor of weaning success. ${ }^{11}$ The secondary outcomes were $\mathrm{V}_{\mathrm{T}}$ and respiratory muscle strength, measured 


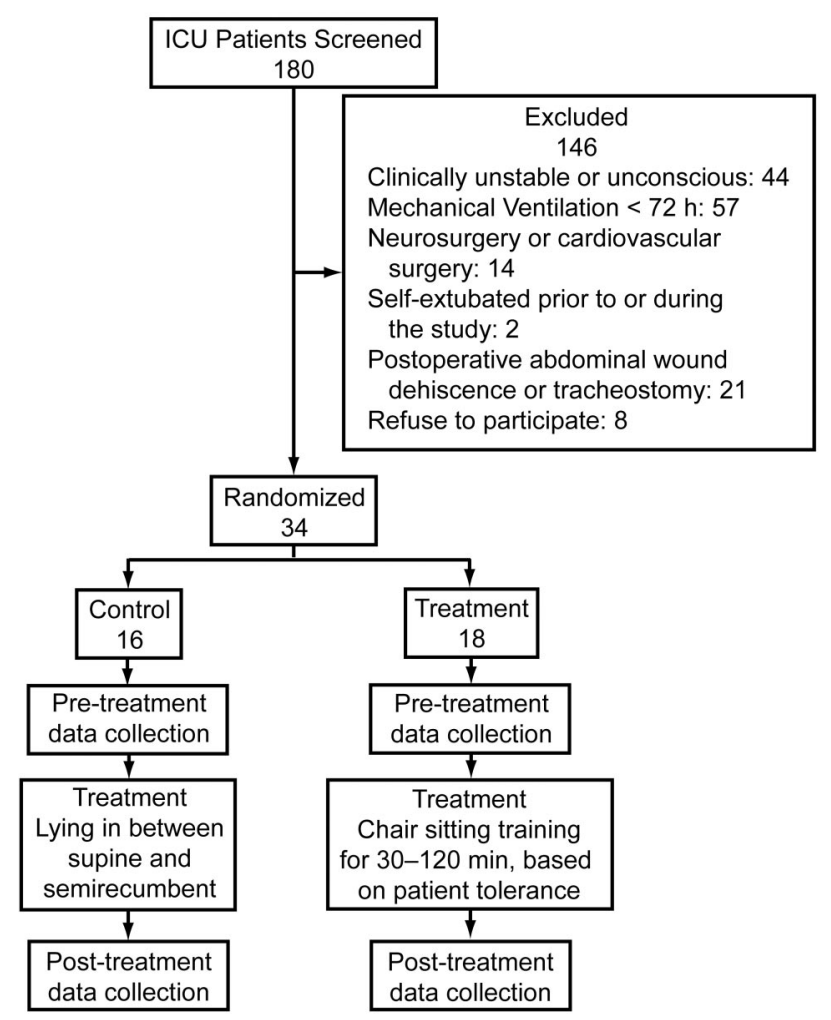

Fig. 1. Flow chart. ICU $=$ intensive care unit.

as inspiratory muscle strength (maximum inspiratory pressure, $\mathrm{P}_{\text {Imax }}$ ), and $\mathrm{P}_{\mathrm{Emax}}$. $\mathrm{V}_{\mathrm{T}}$ and $\mathrm{f}$ were measured with a hand-held respirometer (Haloscale Wright Respirometer, Ferraris Respirometer, Cardinal Health, Dublin, Ohio) while each patient temporarily breathed through a T-piece setup for 60 seconds. Maximum negative inspiratory pressure and $\mathrm{P}_{\mathrm{Emax}}$ were measured with an aneroid manometer while the patient performed maximum static inspiratory and expiratory efforts against an occluded airway. ${ }^{12}$ Heart rate, systolic and diastolic blood pressure, $\mathrm{S}_{\mathrm{pO}_{2}}$, and respiratory rate were continuously measured (Intellivue Patient Monitor, Phillips Medizin System, Boeblingen, Germany) while the patient was in the chair-sitting position.

\section{Statistical Analysis}

An $\mathrm{f} / \mathrm{V}_{\mathrm{T}}$ difference of 20 has been observed between extubation success $(62 \pm 29)$ and extubation failure $(82 \pm 15)$ patients. ${ }^{13}$ A sample size of 16 patients was therefore required in each group to demonstrate a $f / V_{T}$ difference of 20 with a statistical power of $80 \%$ and a 2 -sided $\alpha$ level of $<.05$.

Data were analyzed with statistics software (SigmaStat 2.03, Jandel Scientific, San Rafael, California). In the statistical analysis, missing values were obtained from the previous measured value. Differences in demographic data and clinical outcomes were analyzed with the Student $t$ test.
Table 1. Subjects $(n=34)$

\begin{tabular}{lcc}
\hline \hline & $\begin{array}{c}\text { Chair-Sitting } \\
\text { Group } \\
\text { (no. }=18)\end{array}$ & $\begin{array}{c}\text { Control } \\
\text { Group } \\
\text { (no. }=16)\end{array}$ \\
\hline Age (y) & $65.3 \pm 13.1$ & $66.9 \pm 17.0$ \\
Male/female, no. & $10 / 8$ & $11 / 5$ \\
Body mass index $\left(\mathrm{kg} / \mathrm{m}^{2}\right)$ & $22.8 \pm 3.9$ & $22.4 \pm 3.8$ \\
Blood pressure $(\mathrm{mm} \mathrm{Hg})$ & $137 \pm 19$ & $125 \pm 22$ \\
$\quad$ Systolic & $71 \pm 13$ & $66 \pm 12$ \\
$\quad$ Diastolic & $17.3 \pm 8.3$ & $14.6 \pm 7.6$ \\
APACHE II score at admission & $6.4 \pm 4.0$ & $6.9 \pm 5.3$ \\
ICU ventilator days $(\mathrm{d})$ & $15(83)$ & $13(81)$ \\
Weaning rate, no. $(\%)$ & $2(11)$ & $1(6)$ \\
ICU re-intubation, no. (\%) & $17.5 \pm 9.8$ & $17.5 \pm 11.8$ \\
ICU stay (d) & & \\
& & \\
\pm values are mean \pm SD. & & \\
ICACHE = acute physiology and chronic health evaluation & \\
\hline
\end{tabular}

If data were skewed rather than normally distributed, we calculated the differences with the Mann-Whitney rank sum test. We assessed categorical response variables with the chi-square test, and with the Fisher exact test if the expected frequency was $<5$. We used the paired the Student $t$ test to compare the differences in clinical outcomes and respiratory muscle function before and after treatment. We used linear mixed models to evaluate the effect of treatment and study period, and the interaction of treatment and study period on clinical outcomes and respiratory muscle function. Differences were considered statistically significant when $P<.05$. Values are presented as means $\pm \mathrm{SD}$.

\section{Results}

\section{Subjects}

Of the 180 patients in the surgical ICU who were screened for eligibility, 143 failed to meet the entry criteria. The remaining 34 patients ( 21 males, 13 females) were randomly assigned to either the treatment (chair-sitting) or the control group (Fig. 1 and Table 1). The mean age was 66.1 y (range 34-89 y). The mean ICU ventilator days was $6.7 \mathrm{~d}$ (range 3-24 d). Mean ICU stay was $17.5 \mathrm{~d}$ (range 6.0-41.5 d). The chair-sitting and control groups did not differ in any demographic or clinical variables, including age, sex, blood pressure, APACHE II score, ICU stay, ICU ventilator days, weaning or re-intubation rate, comorbidities, diagnosis, and complications. None of the treatment-group patients received analgesia before the bedto-chair mobilizations. The most common diagnoses at ICU admission were gastrointestinal bleeding, peritonitis, trauma, and cancer of the colon, kidney, bladder, esopha- 


\section{Chair-Sitting Exercise InTERvention}

gus, or lung. The most common comorbidities were heart failure, pulmonary edema, asthma, and COPD.

\section{Responses of Respiratory Muscle Function to Position Changes}

Table 2 summarizes the results. Before the treatment on day 1 , there were no significant differences in the clinical outcomes (ie, heart rate, systolic and diastolic blood pressure) or respiratory muscle function variables (ie, respiratory rate, $\mathrm{V}_{\mathrm{T}}, \mathrm{f} / \mathrm{V}_{\mathrm{T}}, \mathrm{S}_{\mathrm{pO}_{2}}, \mathrm{P}_{\text {Imax }}$, or $\mathrm{P}_{\mathrm{Emax}}$ ) between the 2 groups. Only heart rate significantly increased after chairsitting training on day 2 through day 5 . Respiratory muscle function had improved slightly but not significantly after 6 days of the chair-sitting intervention. The linear mixed models indicated that respiratory rate, $\mathrm{V}_{\mathrm{T}}, \mathrm{f} / \mathrm{V}_{\mathrm{T}}, \mathrm{P}_{\text {Imax }}$, and $\mathrm{P}_{\text {Emax }}$ were significantly affected by the study period, but not with regard to chair-sitting training.

\section{Discussion}

Reduced respiratory muscle strength is a common problem in ventilator-dependent patients. Muscle weakness occurs in a quarter of ICU patients mechanically ventilated for $\geq 7$ days. ${ }^{14}$ Although physiotherapy in mechanically ventilated critically ill patients has a sound physiologic rationale, there are few published data to support its efficacy in the critical care setting. To the best of our knowledge, there are no reported data on the effect of chairsitting on respiratory muscle function in mechanically ventilated post-surgical ICU patients. We found that chairsitting training slightly but not significantly improved respiratory muscle function. However, the study period (days of treatment) could be a factor that affects patients' respiratory muscle function.

Respiratory muscle strength can be improved by muscle training in mechanically ventilated patients. ${ }^{15,16}$ In patients who had failed weaning attempts and underwent respiratory-muscle resistive training, mean $\mathrm{P}_{\text {Imax }}$ improved $42 \%$, from $38 \mathrm{~cm} \mathrm{H}_{2} \mathrm{O}$ to $54 \mathrm{~cm} \mathrm{H}_{2} \mathrm{O} .{ }^{15}$ In our study, however, mean $\mathrm{P}_{\text {Imax }}$ improved not only in our patients with chairsitting training but also in the control patients, and the magnitude of the improvement was even higher in the control group (61\% vs 106\%). The lack of improvement of respiratory muscle function in our chair-sitting treatment group might be due to their low illness severity (mean APACHE II score 17.3) at admission, and the patients had optimistic $\mathrm{S}_{\mathrm{PO}_{2}}, \mathrm{P}_{\text {Imax }}$, and $\mathrm{P}_{\text {Emax }}$ values when they started the chair-sitting training. In addition, the weaning rate was high. Although we anticipated that chair-sitting training would improve respiratory muscle function in our patients with an optimistic clinical condition, it is possible that medical intervention time rather than additional training was the cause of their improved respiratory muscle function.
Chair sitting did not significantly improve inspiratory muscle strength in our patients. Caruso et $\mathrm{al}^{17}$ indicated that overtraining and fatigue might be causes of ineffective inspiratory muscle training in mechanically ventilated critically ill patients. However, fatigue may not have been the confounder in our study. Our patients were transferred from bed to chair and sitting with only brief training. In addition, outcomes were measured before and after the treatment, and the results were similar. With regard to training load, we monitored the patients' heart rate and systolic and diastolic blood pressure throughout the study. In contrast to the results of a previous study, ${ }^{13}$ we found a significant increase in heart rate only when systolic and diastolic blood pressure were not significantly different before and after training. A previous study also found that mobilization (ie, sitting on the edge of the bed, sitting to standing, a standing transfer from the edge of the bed to a chair or walking) significantly increased heart rate and blood pressure and caused a nonsignificant $\mathrm{S}_{\mathrm{pO}_{2}}$ decrease in acutely ill patients. However, those changes were generally of small magnitude and did not require any specific intervention. ${ }^{18}$ The change in heart rate seems to be of minor clinical importance. Overtraining, therefore, can be ruled out.

In the clinical setting, a reduction in $\mathrm{V}_{\mathrm{T}}$ is associated with a gradual increase in respiratory rate, which generates dynamic pulmonary hyperinflation and worsens muscle contractility. ${ }^{19,20} \mathrm{An} \mathrm{f} / \mathrm{V}_{\mathrm{T}}$ of $<105$ is used as a measure of rapid and shallow breathing 20,21 and has been a useful index for predicting weaning outcome. ${ }^{10} \mathrm{f} / \mathrm{V}_{\mathrm{T}}$ is significantly higher in patients who failed weaning. ${ }^{21-23}$ Although there was no significant difference in weaning rate between the 2 groups, chair-sitting training was associated with a significant $f / V_{T}$ increase in our patients. Chair-sitting training, therefore, had no benefit on our patients' respiratory muscle function and might induce an increase in mechanical load to breathe in mechanically ventilated ICU patients.

\section{Limitations}

Our sample size was small. Although we calculated the required sample size prior to the study, and the patients in the chair-sitting group had a slight improvement in respiratory muscle function, the fact that the control patients tended to show a similar improvement suggested that chairsitting did not provide any benefit. Age is probably the main confounder to affect the outcomes. Although there was no significant difference in age between the 2 groups, we still adjusted for age when discussing the data (see Table 2), so the difference was not expected to affect the study results. Another limitation was the short duration of the training. Although our patients' mean $f / \mathrm{V}_{\mathrm{T}}$ did not reach the optimal value $(<105)$ after 6 days of chairsitting training, there was a $9.8 \% \mathrm{f} / \mathrm{V}_{\mathrm{T}}$ reduction. Although a reasonable training period has not been determined for 


\section{ChaIR-SitTing Exercise InTERvention}

Table 2. Physiologic Variables in Chair-Sitting Group Versus Control Group

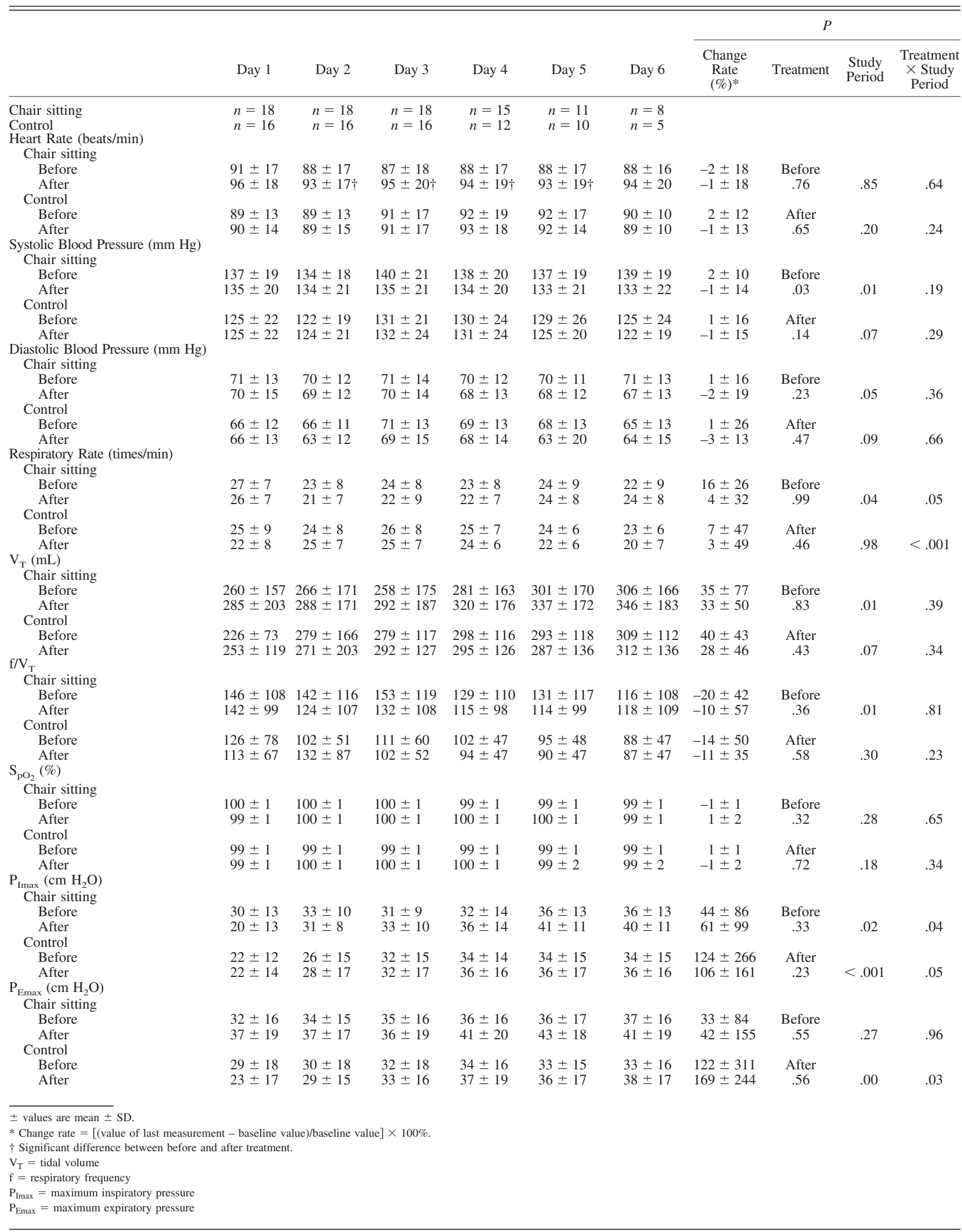




\section{Chair-SitTing Exercise InTERvention}

ventilated ill patients, 6 weeks of physical training does significantly improve respiratory and limb muscle strength in patients on prolonged mechanical ventilation. ${ }^{24}$ Six days of training may not have been sufficient to determine the effect in our patients. A longer training period might significantly improve ventilated patients' respiratory muscle function. The third limitation might be that the intervention was not optimally controlled: the treatments ranged from $30 \mathrm{~min}$ to $120 \mathrm{~min}$, and not all patients received at least once-a-day chair-sitting training. That treatment variation might be too large to allow us to identify a significant effect from the chair-sitting training. A fourth limitation might be that the measurements were made a short time after the completion of the mobilization treatment. In order to avoid measuring any possible immediate, shortterm adverse effects from the mobilization treatment, we took the measurements $30 \mathrm{~min}$ after treatment. The fifth limitation was the blinding. Although this was a randomized controlled trial, the clinicians were not blinded to group assignment. It is possible that the clinicians or patients may have been more motivated in performing chairsitting training. However, the Hawthorne effect could not have occurred, since the results did not support a benefit from chair-sitting training. Finally, we had no "positive" control group (ie, that received other physical therapy), so our finding is only that chair-sitting training was not significantly different from no chair-sitting treatment, and we do not know how the chair-sitting intervention would compare to other respiratory-muscle physiotherapy in mechanically ventilated patients.

\section{Conclusions}

Our ICU patients' respiratory rate, $\mathrm{V}_{\mathrm{T}}, \mathrm{f} / \mathrm{V}_{\mathrm{T}}, \mathrm{S}_{\mathrm{pO}_{2}}, \mathrm{P}_{\mathrm{Imax}}$, and $\mathrm{P}_{\text {Emax }}$ were not significantly improved after 6 days of chair-sitting training, compared to the control patients who received no physiotherapy treatment. Six days of chairsitting training was ineffective for improving respiratory muscle function in mechanically ventilated ICU patients. However, these results do not justify decreased use of ICU physical therapy. More studies are needed on the effect of position change on respiratory muscle function. Respiratory-specific physical therapies, such as paced breathing trials and diaphragm strengthening, might provide greater benefit for mechanically ventilated patients.

\section{REFERENCES}

1. Chao DC, Scheinhorn DJ. Weaning from mechanical ventilation. Crit Care Clin 1998;14(4):799-817.

2. Martin UJ, Hincapie L, Nimchuk M, Gaughan J, Criner G. Impact of whole-body rehabilitation in patients receiving chronic mechanical ventilation. Crit Care Med 2005;33(10):2259-2265.

3. Stiller K. Physiotherapy in intensive care: towards an evidence-based practice. Chest 2000;118(6):1801-1813.
4. Clini E, Ambrosino N. Early physiotherapy in the respiratory intensive care unit. Respir Med 2005;99(9):1096-1104.

5. Dean E. Oxygen transport: a physiologically-based conceptual framework for the practice of cardiopulmonary physiotherapy. Physiotherapy 1994;80(6):347-355.

6. Vellody VP, Nassery M, Druz WS, Sharp JT. Effects of body position change on thoracoabdominal motion. J Appl Physiol 1978;45(4): 581-589.

7. Gounden P. The effect of posture on ventilatory muscle function and lung function. South Afr J Physiother 1986;42:81-84.

8. Jenkins SC, Soutar AS, Moxham J. The effects of posture on lung volumes in normal subjects and in patients with pre- and post-coronary artery surgery. Physiother 1988;74(10):492-496.

9. Burns SM, Egloff MB, Ryan B, Carpenter R, Burns JE. Effect of body position on spontaneous respiratory rate and tidal volume in patients with obesity, abdominal distention and ascites. Am J Crit Care 1994;3(2):102-106.

10. Ogiwara S, Miyachi T. Effect of posture on ventilatory muscle strength. J Phys Ther Sci 2002;14(1):1-5.

11. Tobin MJ, Jubran A. Variable performance of weaning-predictor tests: role of Bayes' theorem and spectrum and test-referral bias. Intensive Care Med 2006;32(12):2002-2012.

12. Caruso P, Friedrich C, Denari SDC, Ruiz SAL, Deheinzelin D. The unidirectional valve is the best method to determine maximal inspiratory pressure during weaning. Chest 1999;115(4):1096-1101.

13. Teixeira C. Zimermann Teixeira PJ. Hoher JA. de Leon PP. Brodt SF. da Siva Moreira J. Serial measurements of $f / V_{T}$ can predict extubation failure in patients with $\mathrm{f} / \mathrm{V}_{\mathrm{T}} \leq 105$ ? J Crit Care 2008; 23(4):572-576

14. De Jonghe B, Sharshar T, Lefaucheur J-P, Authier F-J, Durand-Zaleski I, Boussarsar M, et al. Paresis acquired in the intensive care unit: a prospective multicenter study. JAMA 2002;288(22):2859-2867.

15. Aldrich TK, Uhrlass RM. Weaning from mechanical ventilation: successful use of modified inspiratory resistive training in muscular dystrophy. Crit Care Med 1987;15(3):247-249.

16. Aldrich TK, Karpel JP. Inspiratory muscle resistive training in respiratory failure. Am Rev Respir Dis 1985;131(3):461-462.

17. Caruso P, Denari SDC, Ruiz SAL, Bernal KG, Manfrin GM, Friedrich $\mathrm{C}$, Deheinzelin D. Inspiratory muscle training is ineffective in mechanically ventilated critically ill patients. Clinics 2005;60(6):479-484.

18. Stiller K, Phillips AC, Lambert P. The safety of mobilization and its effect on haemodynamic and respiratory status of intensive care patients. Physiother Theory Pract 2004;20(3):175-185.

19. Cohen C, Zagenbaum G, Gross D, Roussos C, Macklem PT. Clinical manifestations of inspiratory muscle fatigue. Am J Med 1982;73(3): 308-316.

20. Tobin MJ, Perez W, Guenther SM, Semmes BJ, Mador MJ, Allen SJ, et al. The pattern of breathing during successful and unsuccessful trials of weaning from mechanical ventilation. Am Rev Respir Dis 1986;134(6):1111-1118.

21. Yang KL, Tobin MJ. A prospective study of indexes predicting the outcome of trials weaning from mechanical ventilation. N Engl J Med 1991;324(21):1445-1450.

22. Sellares J, Acerbi I, Loureiro H, Dellaca RL, Ferrer M, Torres A, et al. Respiratory impedance during weaning from mechanical ventilation in a mixed population of critically ill patients. Br J Anaesth 2009;103(6):828-832.

23. Maldonado A, Bauer TT, Ferrer M, Hernandez C, Arancibia F, Rodriguez-Roisin R, Torres A. Capnometric recirculation gas tonometry and weaning from mechanical ventilation. Am J Respir Crit Care Med 2000;161(1):171-176

24. Chiang L-L, Wang L-Y, Wu C-P, Wu H-D, Wu Y-T. Effects of physical training on functional status in patients with prolonged mechanical ventilation. Phys Ther 2006;86(9):1271-1281. 